\title{
Treated Wastewater Effluent Reduces Sperm Motility Along an Osmolality Gradient
}

\author{
H. L. Schoenfuss $\cdot$ J. T. Levitt $\cdot$ R. Rai $\cdot$ \\ M. L. Julius · D. Martinovic
}

Received: 22 April 2008/ Accepted: 4 August 2008

(C) Springer Science+Business Media, LLC 2008

\begin{abstract}
Many toxic effects of treated wastewater effluent on organismal and reproductive health have been documented. However, the physicochemical environment of treated wastewater effluent frequently differs considerably from that of its receiving waters and may affect organismal function independently of toxic effects. Teleost sperm, for example, may be affected by the higher osmolality of treated wastewater, as this sperm is activated for a brief period of time following ejaculation due to the sudden decrease in osmolality of its surrounding environment. In this study, we examined the effects of treated wastewater effluent on sperm motility to test the hypothesis that the higher osmolality of effluent compared to river water will adversely affect sperm activation in a concentrationdependent relationship. Treated wastewater effluent was collected on 5 days from the outflow of the Metropolitan Wastewater Treatment Plant, St. Paul, Minnesota, and from an upstream site on the Mississippi River. Milt aliquots collected from goldfish were diluted in an isotonic extender
\end{abstract}

H. L. Schoenfuss · R. Rai · M. L. Julius

Aquatic Toxicology Laboratory, St. Cloud State University, 720 Fourth Avenue South, St. Cloud, MN 56301, USA

H. L. Schoenfuss ( $\square)$

Department of Biological Sciences, WSB-273,

St. Cloud State University, 720 Fourth Avenue South,

St. Cloud, MN 56301, USA

e-mail: hschoenfuss@ @stcloudstate.edu

J. T. Levitt

Department of Natural Resources, Fishing in the Neighborhood Program, 1200 Warner Road, St. Paul, MN 55106, USA

D. Martinovic

Department of Biology, University of St. Thomas, St. Paul, MN

55105, USA solution and subsequently activated in either deionized water, $100 \%, 50 \%$, or $10 \%$ effluent, a synthetic ion mixture, or river water. Sperm motility and velocity were assessed at 15-s intervals for $1 \mathrm{~min}$ using a computer assisted sperm analyzer. Significant differences in performance parameters were found only at $15 \mathrm{~s}$, with sperm motility and velocity declining rapidly at later sampling times. Predictably, deionized water resulted in the greatest activation of sperm motility, while motility exhibited a concentration-dependent decline in $10 \%, 50 \%$, and $100 \%$ treated wastewater effluent. Interestingly, Mississippi River water and a synthetic ion mixture with an osmolality comparable to $50 \%$ effluent both resulted in the least amount of sperm activation. However, sperm activation in river water varied between collection days during the study. River water and 100\% effluent both had low sperm activation characteristics despite a 10 -fold difference in osmolality between these two treatments ( 1 and $10 \mathrm{mO}-$ smol kg-1, respectively). Results of this study indicate a concentration-dependent decrease in sperm motility in treated wastewater effluent as well as significant fluctuations of sperm activation in Mississippi River water. This study illustrates the complexity of assessing the effects of treated wastewater effluents and the difficulty of determining appropriate reference sites for such studies.

Many effects of treated wastewater effluent on the reproductive ability of fish have been examined. However, the ability of freshwater teleost sperm to become motile after ejaculation, a crucial link to the reproductive success in a mating event, has received less attention (Kime 1999; Kime and Nash 1999). While research has more often focused on semen and sperm quality of exposed male fish (Schoenfuss et al. 2002; Lahnsteiner et al. 2005a, b; Runnalls et al. 
2007); recently, several studies have examined the effects of pollutants in effluent on motility parameters of fish sperm (Kime et al. 1996; Rurangwa et al. 2002). These studies, in effect, treated sperm as an independent, short-lived organism (often $<1 \mathrm{~min}$ ) that can be affected by effluent independently of the organism from which it originated. As noted by Kime (1999), successful egg fertilization depends on the first minute of sperm motility induction and can be adversely affected by any pollutant able to reduce sperm motility. In this study, we examined the motility patterns of healthy sperm in several treated wastewater dilutions, a synthetic ion mixture, and river waters to determine whether treated wastewater effluent adversely affects sperm motility in an osmolality-dependent manner.

Most freshwater fish rely on external fertilization, with males and females releasing gametes almost simultaneously into the water column (Petersen and Warner 1998). Fish sperm (in contrast to mammalian sperm) remains immobile until release into the water, at which time the sharp drop in osmolality activates the sperm. This osmolality-dependent cell signaling (Takai and Morisawa 1995) is common to many freshwater teleosts. Once activated, sperm motility persists for only a few seconds or minutes in most freshwater teleosts (Morisawa and Suzuki 1980; Billard et al. 1995). Sperm motility, therefore, becomes an important factor in fertilization success, especially in species that release gametes into the open water column, and even seemingly minor changes in sperm performance may prevent sperm from reaching eggs in the flowing waters of streams (Kime 1999; Kime and Nash 1999). Computer-assisted sperm motility analysis utilizes an automated system to measure several biologically significant parameters of sperm motility quickly and in many sperm at once to provide an excellent representation of the entire ejaculates quality.

Goldfish are commonly used in endocrine and reproductive studies (Kyle et al. 1985; Stacey et al. 1987, 2000), have been used extensively for sperm motility studies (Billard et al. 1995; Krasznai et al. 1995; Marian et al. 2000; Dzuba et al. 2001; Rurangwa et al. 2002; Schoenfuss et al. 2002; Warnecke and Pluta 2003), and are related to many fish species found in North America. The osmotic pressure of goldfish and carp semen is similar, at $\sim 300$ mOsmol kg-1 (Morisawa et al. 1983, 1994), and about $400 \times$ higher than most freshwaters, but only about $30 \times$ higher than many treated wastewater effluents (unpublished data).

Municipal treated wastewater effluents are significant portals for the introduction of aquatic contaminants (Desbrow et al. 1998; Ternes 1998; Ternes et al. 1999; Kolpin et al. 2002) and the resultant effects have been studied extensively (Folmar et al. 1996, 2001; Jobling et al. 1998; Rodgers-Gray et al. 2000, 2001; Schoenfuss et al. 2002). Although these contaminants affect the exposed organism in different ways and through varying exposure routes, effluents may affect aquatic organisms simply through changing the organism's physicochemical environment. Temperature effects of treated wastewater effluent have been discussed by other authors (Coutant 1970; Alavi and Cosson 2005) and are an example of the effluent's physical alteration of the aquatic environment. In addition, the higher osmolality of many wastewater effluents may affect sperm motility, which is initiated upon ejaculation in freshwater teleosts as a result of the hypotonicity of the surrounding water (Billard et al. 1995; Takai and Morisawa 1995). If fish spawn in river sections receiving treated wastewater effluent and if sperm fails to achieve full motility quickly, then fertilization rates and, ultimately, reproductive ability should be adversely affected (Billard 1978; Stoss 1983).

In order to test the hypothesis that the higher osmolality of effluent compared to river water will adversely affect sperm activation in a concentration-dependent relationship, we designed a study to address two objectives: (1) to determine whether goldfish sperm activation and motility are adversely affected when activated in graded concentrations of treated wastewater effluent and (2) whether the activation pattern can be explained by the osmolality gradient of the effluent.

\section{Materials and Methods}

\section{Experimental Design}

The Metropolitan Wastewater Treatment Plant (Metro WWTP), St. Paul, Minnesota, USA, was chosen for this study, as it is the largest wastewater treatment plant on the Upper Mississippi River and utilizes tertiary wastewater effluent treatment (Robert Polta, Metro WWTP, St. Paul, $\mathrm{MN})$. In addition, the treated effluent is discharged into a quasi-natural channel of considerable length that attracts many species of fish, including several commercially important species of fish (e.g., walleye, Stizostedion vitreum) as well as a variety of other native and nonnative (e.g., common carp, Cyprinus carpio) species.

Goldfish sperm was collected and placed in an isotonic sperm extender solution (Chao et al. 1987). Sperm was later activated on the stage of an automated Hamilton-Thorn Sperm Analyzer (HTM 2030,; Biogenics, Napa, CA, USA), capable of tracking the movement of $>200$ gametes simultaneously (Liu et al. 1991). Sperm was activated by diluting an aliquot of the extender solution in the following treatments: (1) control-200 $\mu \mathrm{L}$ deionized water; (2) $100 \%$ effluent $-200 \mu \mathrm{L}$ undiluted treated wastewater effluent (Metro WWTP); (3) $50 \%$ effluent $-100 \mu \mathrm{L}$ effluent diluted in equal amounts of deionized water; (4) $10 \%$ effluent-20 $\mu \mathrm{L}$ effluent in $180 \mu \mathrm{L}$ 
deionized water; (5) synthetic ion mixture-200 $\mu \mathrm{L}$ containing many of the most prominent ions central to sperm motility (the total osmolality of the synthetic ion mixture was designed to fall in the range of Metro WWTP effluent osmolality based on prior analysis of this effluent); and (6) Mississippi River water-200 $\mu \mathrm{L}$ collected at the same time as the effluent.

Following activation, the quality of the ejaculate (total sperm, percentage rapid sperm) and sperm motility (velocity and lateral head displacement) was assessed for each sample at 15-s intervals, at 15, 30, 45, and $60 \mathrm{~s}$. Triplicate analyses were conducted for each sample at each time interval (total of 1800 analyses; 25 fish $\times 4$ times $\times 6$ solutions $\times 3$ replicates). On each of the 5 analysis days, sperm from five goldfish was activated in the six treatments. This experimental design enabled us to measure sperm activation and motility across all treatments using the same semen sample from one fish and repeat this process for 25 individuals.

\section{Treatments}

Effluent for this study was collected in the morning of each of the 5 analysis days directly from the effluent discharge site of the Metro WWTP. Effluent temperature was recorded and a 1-L sample was collected in a Nalgene bottle. Upon return to the laboratory (within $1 \mathrm{~h}$ from sample collection), a portion of the sample was dispensed into 2.5$\mathrm{mL}$ centrifuge tubes to prepare $200-\mu \mathrm{L}$ aliquots of graded wastewater effluent dilutions. Deionized water was added as necessary to establish aliquots of $100 \%, 50 \%$, and $10 \%$ wastewater effluent. Mississippi River water was collected $2 \mathrm{~km}$ upstream of the effluent discharge site in downtown ST. Paul (Fig. 1). River water samples were also dispensed as $200-\mu \mathrm{L}$ aliquots into $2.5-\mathrm{mL}$ microcentrifuge tubes. In addition, we prepared a synthetic ion mixture to simulate the osmolality of the effluent (measured previously) while excluding the overwhelming majority of potentially toxic compounds in the treated wastewater effluent. The synthetic ion mixture was based only on the ions of calcium, potassium, chloride, and sodium, which are documented to be central to sperm activation and motility (Alavi et al. 2007). All aliquots $(\sim 30$ aliquots for each treatment per analysis day) were stored at $4^{\circ} \mathrm{C}$ until being used for sperm activation (within $3 \mathrm{~h}$ of dilution).

Effluent and river water from all 5 sampling days, deionized water, and a sample of the synthetic ion mixture were frozen immediately after collection and later analyzed by the Research Analytical Laboratory of the University of Minnesota for cation, anion, and metal content. Samples were digested with $5 \% \mathrm{HNO}_{3}$ for $1 \mathrm{~h}$ in a digestion block prior to analysis (EPA Method 200.7; U.S. Environmental Protection Agency 1983). Ionic concentrations were determined simultaneously by inductively coupled plasma

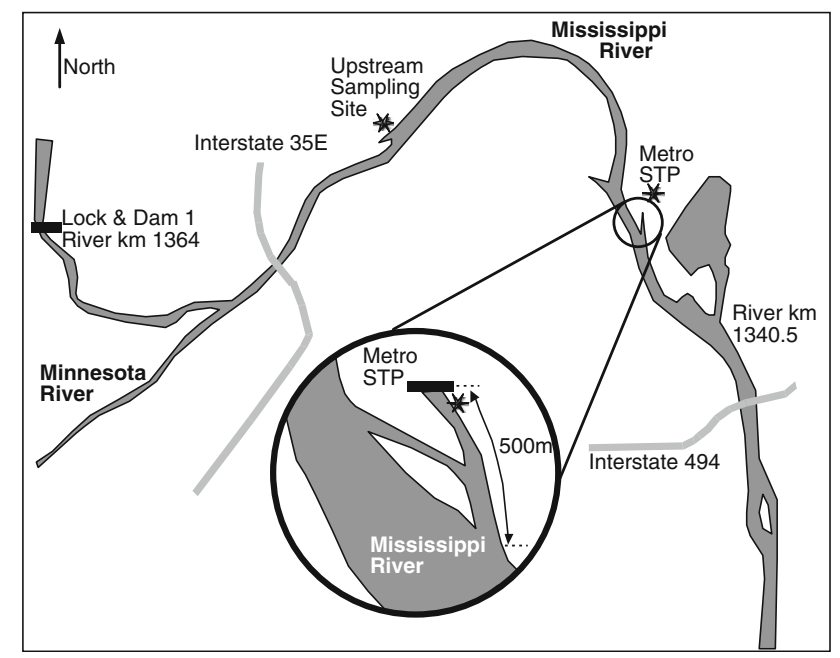

Fig. 1 Sampling sites at the Metropolitan Wastewater Treatment Plant, St. Paul, Minnesota, and upstream at the Mississippi River. Illustration not to scale

(ICP) atomic emission spectrometry (Fassel and Kniseley 1974). Osmolality was determined for the same series of samples using a freezing-point depression osmometer (Osmette, Precision Systems; analysis conducted by Dr. Glen Parsons, University of Mississippi).

\section{Animals and Sperm Collection}

Mature male goldfish (10- to $12-\mathrm{cm}$ total length) were obtained several months prior to the experiments from Hunting Creek Fisheries (Thurmont, MD, USA) and maintained under constant laboratory conditions $(16: 8 \mathrm{~h}$ light:dark; fed ad libitum flake food [ChemAqua, Oxnard, CA, USA]). Groups of 8-10 male goldfish that had expressed milt throughout the holding period were stimulated $12 \mathrm{~h}$ before sperm was collected using both waterborne pheromonal $\left(10^{-10} \mathrm{~mol}\right.$ of $17 \alpha, 20 \beta$-dihydroxy4-pregnen-3-one, a preovulatory pheromone released by the female goldfish) and behavioral stimuli (addition of a mature female goldfish) to maximize sperm production (DeFraipont and Sorensen 1993). One hour after lights-on $(0700 \mathrm{~h})$, male goldfish were removed from the aquarium and lightly anesthetized ( $0.1 \%$ phenoxyethanol), and milt (sperm and seminal fluids) was collected by applying light abdominal pressure and aspirating sperm from the genital pore. Great care was taken not to contaminate the sperm sample with fish urine or feces, as these would cause a premature activation of the sperm. Based on milt availability and abundance, milt from five goldfish was used for each day's analysis. Animal husbandry followed IACUC guidelines and protocols filed for similar studies at the University of Minnesota.

Milt from each of the five fish was collected separately and briefly stirred to assure sample homogeneity. A $4-\mu \mathrm{L}$ 
sample was then pipetted into $400 \mu \mathrm{L}$ sperm extender solution $(100 \times$ dilution) (Chao et al. 1987) and stored at $4^{\circ} \mathrm{C}$ until the time of analysis (usually within $3 \mathrm{~h}$ ). Previous studies have indicated that sperm stored under such conditions does not degrade significantly for at least $24 \mathrm{~h}$ (Schoenfuss et al. 2002).

\section{Sperm Analysis}

For the sperm motility analysis in all treatments, $10 \mu \mathrm{L}$ sperm extender solution was added to the treatment-specific $200-\mu \mathrm{L}$ aliquot of diluted wastewater effluent, river water, synthetic ion mixture, or deionized water control, resulting in a final dilution of the sperm sample of 1:2000. The final diluted sample was briefly agitated to ensure homogeneity before a $7-\mu \mathrm{L}$ sample of the dilution was pipetted onto the stage of the sperm analyzer. A stopwatch was used to start the analysis at the appropriate time intervals $(15,30,45$, and $60 \mathrm{~s})$. All analyses were conducted at room temperature $\left(22^{\circ} \mathrm{C}\right)$, as temperature can influence sperm motility (Alavi and Cosson 2005).

Several parameters of the ejaculate and sperm motility contribute to the likelihood of sperm successfully reaching and fertilizing an egg (Kime et al. 1996, 2001; Warnecke and Pluta 2003). These include the percentage of motile sperm in a sample (even under the best activation conditions, up to $40 \%$ of goldfish sperm will remain nonmotile due to age or maturation status) and the percentage of rapidly motile sperm (mean progressive velocity, $>30 \mu \mathrm{m} \mathrm{s}^{-1}$ ) to eliminate nonmotile sperm as a factor in the analysis. Two measures of the actual movement of a sperm are critical to the sperms' ability to reach an egg. First, the distance, in a straight line, that a sperm progresses from the beginning of the analysis to its completion is considered the most reliable indicator of sperm fertility in mammals (Moore and Akhondi 1996) (measured as progressive velocity; $\mu \mathrm{m} \mathrm{s}^{-1}$ ). Second, the velocity of the sperm along its actual path (in contrast to the straight line measure) is reflective of the sperm swimming performance (path velocity). Finally, sperm with asymmetric morphology or other pathological changes will swim in a less fluent mode and display greater lateral movement than normal sperm (lateral head displacement Kime et al. 1996). Together, these parameters allow an assessment of the ability of sperm to become activated and move quickly toward an egg during the short fertilization window.

Care was taken to analyze samples in order to avoid the introduction of a sampling bias. Thus, all six treatments at all four times were run sequentially with sperm from the first fish, then the second, and so forth. This was repeated two more times to complete the triplicate analyses. Only the highest sperm performance for each treatment and fish, rather then the average of each triplicate analysis, was selected for the statistical analysis. The selection of only the highest performance among multiple observations is consistent with the functionality of sperm activation (which only occurs once) and the biomechanical performance literature, which assumes that unique behaviors are likely underestimated in laboratory settings, but cannot be overestimated due to the physiological and mechanical constraints of the observed organism (i.e., sperm) (Full et al. 1995; Farley 1997; Swanson et al. 1998; Wilson et al. 2000; Carroll et al. 2004).

\section{Statistical Analysis}

The differences between quality parameters of the sperm activated with deionized water, three dilutions of the wastewater effluent, the synthetic ion mixture, and river water were analyzed with repeated-measures ANOVA (STATISTICA 7.1; StatSoft Inc., Tulsa, OK, USA). Time elapsed from the sperm activation was designated a repeatedmeasures factor. Post hoc comparisons were performed using Tukey's test. Differences between sperm quality parameters activated with river water collected during two discrete sampling periods were also analyzed with repeatedmeasures ANOVA, with time elapsed from the sperm activation as a repeated-measures factor. For all statistical tests the differences were considered significant at $p<0.05$.

\section{Results}

\section{Osmolality}

Osmolality varied significantly (ANOVA; $p<0.0001$ ) between treatments (Fig. 2). Deionized water had no detectable osmolality (detection limit: $0.1 \mathrm{mOsm} \mathrm{kg}^{-1}$ ), while undiluted wastewater effluent had the highest mean osmollity, at $9.8 \mathrm{mOsm} \mathrm{kg}^{-1}$. As expected, osmolality decreased with dilution of wastewater effluent to 4.88 and $1 \mathrm{mOsm} \mathrm{kg}^{-1}$ in the $50 \%$ and $10 \%$ treatments, respectively. The osmolality of river water was low and varied between analysis days from 0 to $2.33 \mathrm{mOsm} \mathrm{kg}{ }^{-1}$ (average of three measures for each sampling day). The synthetic ion mixture included to provide a solution similar in osmolality to effluent was found to have a total osmolality of $6.6 \mathrm{mOsm} \mathrm{kg}^{-1}$ or on average $30 \%$ less then $100 \%$ effluent. Although the osmolality of the synthetic ion mixture did not match the effluent osmolality as closely as expected (due to changes in effluent osmolality from the time when the preliminary analysis of the effluent was conducted and the time when the actual experiment commenced), it was sufficient to assess whether diminished sperm performance in effluent could be related to osmolality or to toxic effects of the effluent. Due to the variability of the effluent osmolality, the 


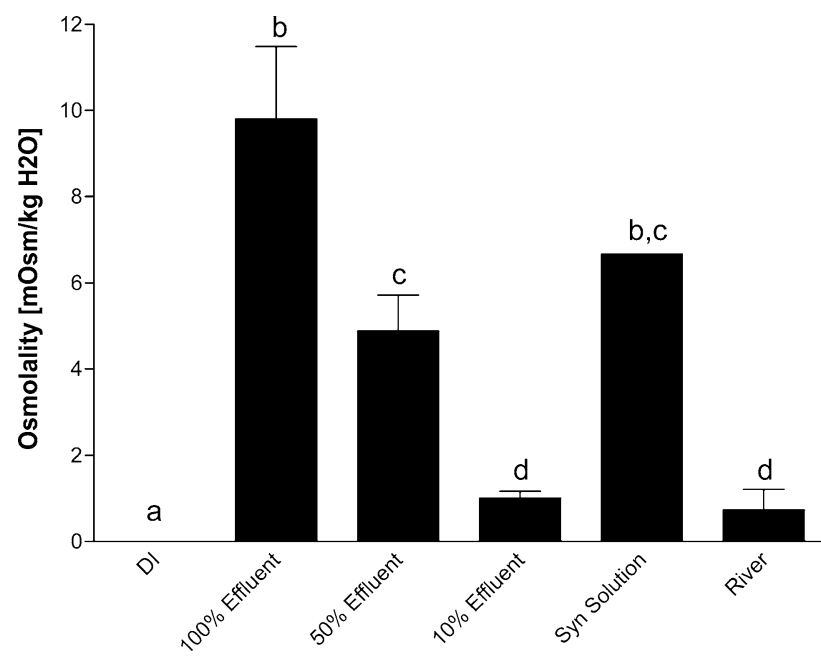

Fig. 2 Activation solution osmolalities (mOsm kg $\mathrm{kg}^{-1} \pm \mathrm{SE}$ ) for sperm motility experiment. Different letters indicate significant differences between treatments at $p<0.05$ (ANOVA, Tukey's multiple-comparison posttest). The synthetic effluent does not carry an error bar since the same solution was used in all replicates of the experiment

difference between $100 \%$ effluent and the synthetic ion mixture was not significant at $p<0.05$. The mean osmolality of Mississippi River water was $0.733 \mathrm{mOsm} \mathrm{kg}^{-1}$ across all days and replicates.

\section{Ionic Concentration}

Of the 15 elements tested, 5 were below detection limits for all samples ( $n=5$ each for effluent and river water): cadmium (0.006 $\mathrm{mg} \mathrm{L}^{-1}$ detection limit), chromium (0.014 mg L $\left.{ }^{-1}\right)$, copper (0.026 mg L $\left.{ }^{-1}\right)$, nickel (0.022 mg $\left.\mathrm{L}^{-1}\right)$, and lead $\left(0.084 \mathrm{mg} \mathrm{L}^{-1}\right)$. Magnesium concentrations were similar in effluent $(n=5)$ and river water $(n=5$; $21 \pm 0.8 \mathrm{mg} \mathrm{L}^{-1}$ ). Four elements exhibited consistent differences in concentrations between the two sampling sites (Table 1), while the remaining five elements varied between sites and, in some cases, between sampling dates at a site (Tables 1 and 2). The contribution of specific cations, most notably potassium and sodium, to the osmolality of the test media varied considerably (Tables 1 and 2). For undiluted wastewater effluent potassium varied between 10.32 and $13.58 \mathrm{mg} \mathrm{L}^{-1}$ across the 5 sample days, while sodium concentrations varied between 125.76 and $143.42 \mathrm{mg} \mathrm{L}^{-1}$. As deionized water was used to dilute effluent for the $50 \%$ and $10 \%$ effluent samples, the concentrations for sodium and potassium were approximately one-half and one-tenth the values for the $100 \%$ effluent. Cation concentrations also varied among the 5 sampling days of river water. Potassium concentrations in river water varied between 2.84 and $3.63 \mathrm{mg} \mathrm{L}^{-1}$, while sodium concentrations ranged from 8.60 to $11.90 \mathrm{mg} \mathrm{L}^{-1}$.

A noticeable difference in cation and metal concentrations was observed between days 1 and 2 and the following three sampling days (Table 2) and may be related to a rain event in the collection area before the first sample day ( $4 \mathrm{~cm}$ rain just prior to the first sample collection on June 24,2002 ), while the following 3 collection days occurred during dry weather conditions (one rain event, $5 \mathrm{~cm}$, occurred just after the July 10, 2002, river water collection).

\section{Sperm Motility}

The majority of male goldfish (over $80 \%$ ) provided ample milt $12 \mathrm{~h}$ after stimulation. The activation of over $65 \%$ of sperm in any given milt sample (data not shown) was comparable to that reported in previous studies (Billard 1995; Christ et al. 1996) and the initial speed at which sperm traveled along its trajectory (mean path velocity) when activated in deionized water matched that for carp recorded in previous studies (Rurangwa et al. 2002). Total

Table 1 Selected ion and metal concentrations $\left(\mathrm{mg} \mathrm{L}^{-1}\right)$ : concentrations averaged over 5 sampling days for river and effluent samples

\begin{tabular}{lcccc}
\hline Element & $\begin{array}{l}\text { Synthetic ion } \\
\text { mixture }^{\mathrm{a}}\end{array}$ & $\begin{array}{l}\text { River } \\
\text { mean } \pm \text { SE }(n)\end{array}$ & $\begin{array}{l}\text { Effluent } \\
\text { mean } \pm \text { SE }(n)\end{array}$ \\
\hline Manganese & $<0.19$ & $0.2 \pm 0.04(5)$ & $0.05 \pm 0.005(5)$ & 0.017 \\
Phosphorus & 2.76 & $0.2 \pm .0 .3(5)$ & $2 \pm 0.1(5)$ & 0.0004 \\
Zinc & $<0.01$ & $0.02 \pm 0.002(5)$ & $0.05 \pm 0.005(5)$ & 0.004 \\
Boron & $<0.02$ & $0.04 \pm 0.002(5)$ & $75.13 \pm 1.7(5)$ & $0.001(5)$ \\
Calcium & 16.66 & $56.96 \pm 4.1(5)$ & $12.73 \pm 0.67(5)$ & 0.003 \\
Potassium & 7.21 & $3.35 \pm 0.13(5)$ & $135.8 \pm 3.93(5)$ & $0.18 \pm 0(5)$ \\
Sodium & 163.37 & $10.1 \pm .62(5)$ & $0.16 \pm 0.02(5)$ & $\mathrm{n}$
\end{tabular}

Values preceded by " $<$ " indicate concentrations below the detection limit

a The same synthetic ion mixture was used on all 5 days and, therefore, was only analyzed once

$p$ values indicate significance of differences between ion concentrations in river water and $100 \%$ effluent (unpaied t-test) 
Table 2 Selected cation and metal concentrations $\left(\mathrm{mg} \mathrm{L}^{-1}\right)$ for the five sampling days

\begin{tabular}{|c|c|c|c|c|c|}
\hline \multirow[t]{2}{*}{ Sampling site and day } & \multicolumn{3}{|l|}{ Cation } & \multicolumn{2}{|c|}{ Metal } \\
\hline & $\mathrm{Ca}$ & $\mathrm{K}$ & $\mathrm{Na}$ & $\mathrm{Al}$ & $\mathrm{Fe}$ \\
\hline \multicolumn{6}{|l|}{ Mississippi } \\
\hline 24 June 02 & 68.47 & 3.43 & 11.90 & 1.23 & 2.76 \\
\hline 26 June 02 & 61.56 & 3.33 & 10.10 & 1.05 & 2.41 \\
\hline 2 July 02 & 54.14 & 3.63 & 8.59 & 0.30 & 0.89 \\
\hline 10 July 02 & 49.10 & 3.50 & 8.92 & 0.18 & 0.60 \\
\hline 31 July 02 & 48.55 & 2.87 & 11.01 & 0.18 & 0.48 \\
\hline \multicolumn{6}{|l|}{ Effluent } \\
\hline 24 June 02 & 72.95 & 10.32 & 126.74 & 0.18 & 0.12 \\
\hline 26 June 02 & 79.92 & 12.29 & 125.76 & 0.18 & 0.20 \\
\hline 2 July 02 & 76.29 & 13.56 & 142.10 & 0.18 & 0.13 \\
\hline 10 July 02 & 70.15 & 13.88 & 143.42 & 0.18 & 0.14 \\
\hline 31 July 02 & 76.36 & 13.59 & 141.10 & 0.18 & 0.19 \\
\hline
\end{tabular}

sperm concentration was not significantly different among the six treatments, ranging in value from approximately $4 \times 10^{4}$ to $6 \times 10^{4}$ sperm $\mathrm{mL}^{-1}$ (data not shown). This was expected, as the sperm activated in all treatments came from the same fish. Lateral head displacement did not differ between treatments (Fig. 3a), indicating that sperm movement was bilaterally symmetrical and void of any morphological abnormalities. Any significant differences in sperm performance parameters between treatments were found at the 15-s measurement interval, reflecting the rapid decline in sperm motility within $30 \mathrm{~s}$ after activation.

The concentration of sperm in each sample that exhibited any movement differed significantly among treatments at the 15 -s interval $(p<0.0001$, ANOVA with Tukey posttest; $n=25$ for all treatments). The highest concentration of motile sperm at $15 \mathrm{~s}$ was recorded in deionized water (mean: $59.7 \times 10^{3} \pm 7.9 \times 10^{3}$ sperm $\mathrm{mL}^{-1}$ ), and it declined for the other treatments in the following order: synthetic ion mixture $\left(40 \times 10^{3} \pm 4.1 \times 10^{3}\right), 50 \%$ effluent $(37.3 \times$ $\left.10^{3} \pm 3.3 \times 10^{3}\right), 10 \%$ effluent $\left(35.6 \times 10^{3} \pm 3.9 \times 10^{3}\right)$, $100 \%$ effluent $\left(29.6 \times 10^{3} \pm 3.4 \times 10^{3}\right)$, and river water $\left(28.2 \times 10^{3} \pm 2.5 \times 10^{3}\right)$. Similarly, the number of sperm that move swiftly after activation (rapid motility) differed significantly ( $p<0.0001 ; n=25$ for all treatments) among treatments at the 15-s interval (Fig. 3b). The highest percentage of rapidly motile sperm was recorded in deionized water $(64 \pm 3 \%$, mean $\pm \mathrm{SE})$, with declining percentages for the other treatments: synthetic ion mixture $(58 \pm 3.3 \%)$, $10 \%$ effluent $(58 \pm 3.7 \%), 50 \%$ effluent $(53 \pm 2.5 \%)$, river water $(40 \pm 3.8 \%)$, and $100 \%$ effluent $(38 \pm 3.2 \%)$.

When measuring the actual speed of sperm along a straight line (progressive velocity) and along their more convoluted path (path velocity), similar, and statistically significant, differences among treatments were observed at
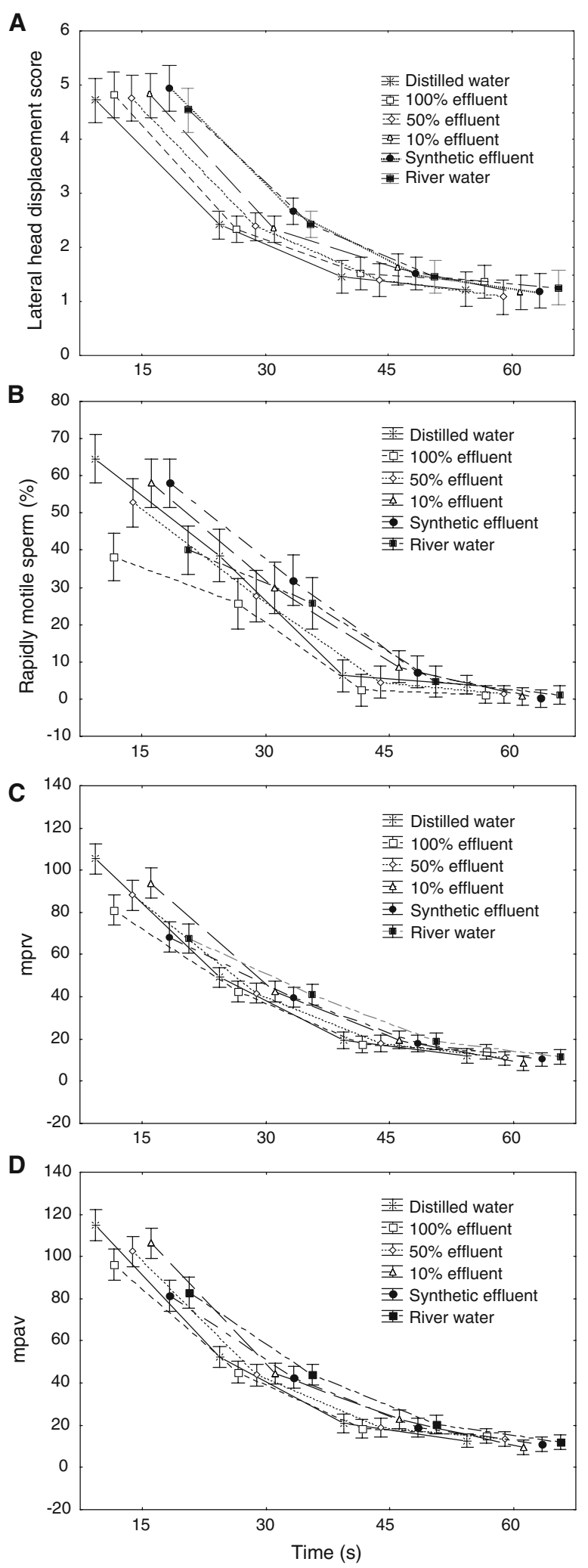

Fig. 3 Sperm motility parameters across four time intervals and six treatments. (a) Lateral head displacement; (b) rapidly motile sperm, as percentage of total sperm count; (c) mprv, mean progressive velocity $\left(\mu \mathrm{m} \mathrm{s}^{-1}\right)$; (d) mpav, mean path velocity $\left(\mu \mathrm{m} \mathrm{s}^{-1}\right) . n=25$ for all times and treatments. Values for the six treatments are spaced out across each time interval to facilitate reading 
Fig. 4 Sperm motility parameters across four time intervals for sperm activated in river water. Solid line indicates subsample of sperm activated in Mississippi River water on the first 2 days of analysis, coinciding with the rain event $(n=1)$; dashed line indicates subsample from days 3-5 $(N=15)$. (a) Lateral head displacement; (b) rapidly motile sperm, as percentage of total sperm count; (c) mprv, mean progressive velocity $\left(\mu \mathrm{m} \mathrm{s}^{-1}\right)$; (d) mpav, mean path velocity $\left(\mu \mathrm{m} \mathrm{s}^{-1}\right) \cdot n=10$ fish for rain event, 15 fish for dry period

$15 \mathrm{~s}$ post motility induction $(p<0.001$, ANOVA with Tukey post test; $n=25$ for all treatments). Mean progressive velocity at $15 \mathrm{~s}$ (Fig. 3c) was highest for deionized

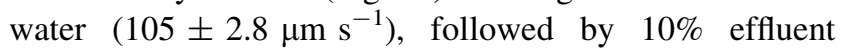
$(94 \pm 3.8), \quad 50 \%$ effluent $(88 \pm 3.5), \quad 100 \%$ effluent $(81 \pm 3.8)$, the synthetic ion mixture $(68 \pm 3.1)$, and river water $(68 \pm 4.3)$ (Fig. 3c). Mean path velocity at $15 \mathrm{~s}$ (Fig. 3d) also was highest for deionized water (115 \pm $2.9 \mu \mathrm{m} \mathrm{s}^{-1}$ ), followed by $10 \%$ effluent (106 \pm 3.7$), 50 \%$ effluent (102 \pm 3.3$), 100 \%$ effluent $(96 \pm 4.3)$, river water $(83 \pm 4.5)$, and the synthetic ion mixture $(81 \pm 3)$ ( $p<0.001 ; n=25$ for all treatments).

It is noteworthy that for sperm activated in Mississippi River water (Fig. 4), the percentage rapidly motile sperm was greater on sampling days 1 and 2 compared to the mean of days 3 through 5 (unpaired Student's $t$-test at $p<0.05 ; n=10$ and $n=15$, respectively). Mean progressive velocity and mean path velocity also averaged significantly lower on sampling days 1 and 2 (55 \pm 4 and $72 \pm 4.8 \mu \mathrm{m} \mathrm{s}^{-1}$, respectively) than days 3 through 5 $\left(76 \pm 5.7\right.$ and $90 \pm 6.2 \mu \mathrm{m} \mathrm{s}^{-1} ; n=10$ and $n=15$, respectively).

\section{Discussion}

Sperm activation and motility upon ejaculation in freshwater teleost fish are closely linked to a sudden decrease in osmolality of the surrounding environment. We expected and found a marked decline in activation and motility in sperm suspended in treated wastewater effluent solutions with increasing osmolality. More surprising, however, was the poor performance of sperm activated in Mississippi River water, even though the osmolality of river water was more similar to that of deionized water and $10 \%$ effluent than the treatments of higher osmolality (Fig. 5). Furthermore, we documented a marked difference in sperm

\begin{tabular}{|c|c|c|c|c|c|c|}
\hline $\begin{array}{l}\text { Performance } \\
\text { at } 15 \mathrm{sec}\end{array}$ & \multicolumn{3}{|c|}{$\begin{array}{l}\text { increased sperm } \\
\text { performance }\end{array}$} & & \multicolumn{2}{|c|}{$\begin{array}{l}\text { decreased sperm } \\
\text { performance }\end{array}$} \\
\hline Sperm concentrations & \multicolumn{6}{|c|}{ no sigificant differences } \\
\hline Lateral head displacement & \multicolumn{6}{|c|}{ no sigificant differences } \\
\hline Motile sperm & DI & Synthetic & $50 \%$ & $10 \%$ & $100 \%$ & River \\
\hline Rapidly motile sperm & DI & Synthetic & $10 \%$ & $50 \%$ & River & $100 \%$ \\
\hline Mean progressive velocity & DI & $10 \%$ & $50 \%$ & $100 \%$ & Synthetic & River \\
\hline Mean path velocity & $\mathrm{DI}$ & $10 \%$ & $50 \%$ & $100 \%$ & River $\mathrm{S}$ & Synthetic \\
\hline
\end{tabular}

Fig. 5 Comparison of sperm performance parameters at $15 \mathrm{~s}$
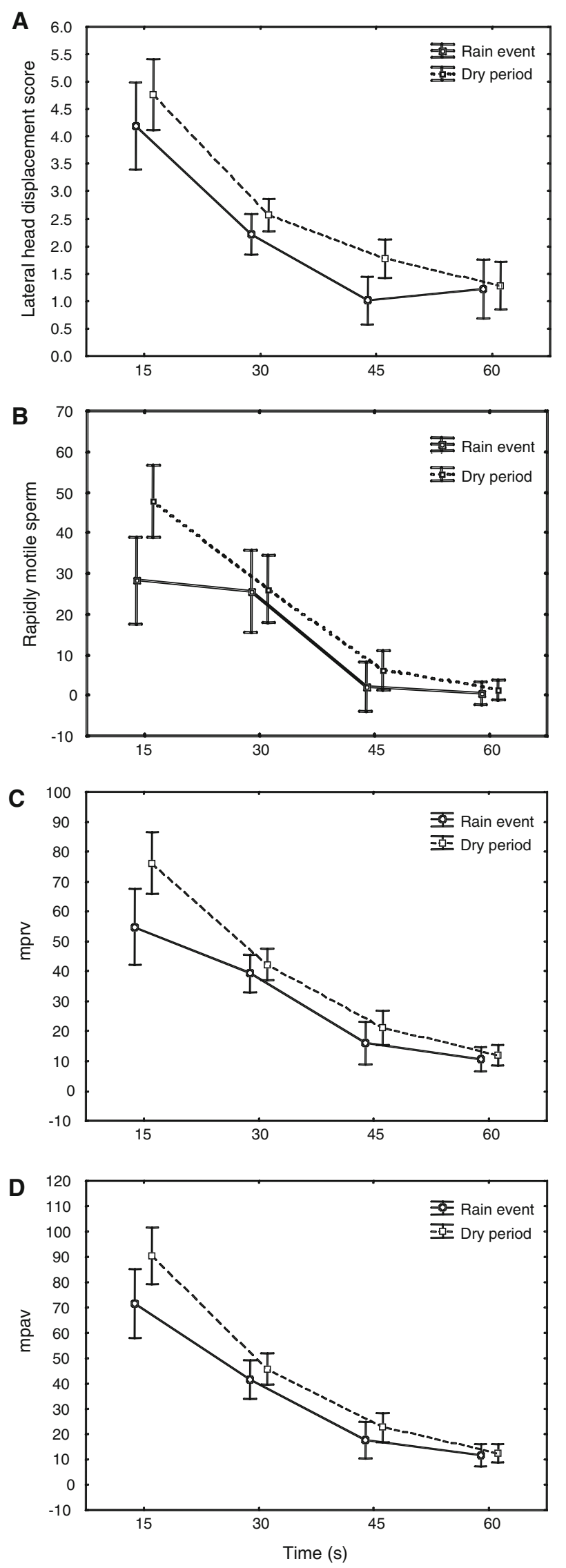
activation and motility in river water collected on the days immediately following a storm event compared to the later sampling days during a dry weather period. Finally, the synthetic ion mixtures included in this experiment to mimic an osmolality similar to that of effluent resulted in substantially different activation and sperm motility patterns than in the two effluent treatments bracketing this mixture in osmolality.

If the results of the effluent dilution series are considered alone, osmolality appears to play a very influential role on sperm motility, as all parameters of sperm performance that should be affected by the increasing osmolality of the effluent series decline in an osmolality-dependent order $(\%$ rapid sperm, mean progressive velocity, mean path velocity). This result is consistent with a large body of published literature which indicates that osmolality has an inverse relationship with sperm motility and velocity (Morisawa 1994; Billard et al. 1995; Krasznai et al. 1995, 2000; Takai and Morisawa 1995). It is unlikely that this effect is simply a function of increased toxicity due to the higher wastewater effluent concentration since the amplitude of lateral head displacement did not vary significantly among treatments. Although the synthetic ion mixture exhibited higher means for rapidly moving sperm and total numbers of activated sperm, mean progressive and mean path velocities of sperm activated in $100 \%$ effluent were higher than those for sperm activated in the synthetic ion mixture, free of most of the potential toxins likely found in the effluent, and despite the synthetic ion mixture's lower osmolality.

Although the differences in velocity appear small, a rough calculation of the total distance traveled by a sperm activated in $10 \%$ effluent vs. $100 \%$ effluent indicates an $\sim 300-\mu \mathrm{m}$ difference in favor of the $10 \%$ effluent-activated sperm over the first $30 \mathrm{~s}$ after activation ( 3180 vs. $2880 \mu \mathrm{m}$ for $10 \%$ and $100 \%$ effluent activated sperm, respectively, based on average mean path velocity). Considering the diameter of a goldfish egg, $\sim 1000 \mu \mathrm{m}$ (Astanin and Podgornyy 1968), the distance to travel from one pole of the egg to the other (containing the micropyle) can be as much as $1500 \mu \mathrm{m}$, or more than half the entire distance a sperm will travel during its rapid active phase. Thus, even though the differences in osmolality between $10 \%$ and $100 \%$ effluent are orders of magnitude smaller then the difference between these media and the internal osmolality of the fish in which sperm remains immotile, the effects of the small difference in osmolality between activation media $\left(9 \mathrm{mOsm} \mathrm{kg}{ }^{-1}\right)$ may determine whether a sperm successfully reaches the micropyle of an egg. This effect is further magnified by the decreased number of sperm becoming rapidly motile with increased osmolality of the activation solution. One-third less rapidly active sperm were found in the treatment activated by $100 \%$ effluent compared to $10 \%$ effluent. The combination of fewer rapidly active sperm and slower maximum velocities may result in a marked reduction of fertilized eggs even if the solution's osmolality is not sufficient to fully inhibit sperm motility.

The linear relationship between sperm activation and effluent concentration indicates the role of osmolality in sperm activation. Although osmolality clearly has an effect on sperm activation, this effect is not mediated equally by all cations and anions. Tan-Fermin et al. (1999) demonstrated that sperm motility was significantly enhanced based on the potassium content of various isotonic solutions composed of $\mathrm{NaCl}$ and $\mathrm{KCl}$, indicating that increased potassium concentrations actually enhance sperm motility despite similar osmolality, while chloride does not appear to affect sperm motility beyond its contribution to the overall osmolality of the activation medium. These data are important when considering the differing sperm activation results for effluent and river water. Sperm activated in 50\% effluent outperformed river water-activated sperm in motility and velocity. Calcium, sodium, and potassium were consistently the dominant cations in effluent and river water samples. Although the osmolality of river water was comparable to the $10 \%$ effluent treatment, potassium concentrations in river water were three times higher and should have resulted in higher motility and velocity of river water-activated sperm. The lack of this response suggests that components of treated wastewater effluent may have a mediating factor on sperm. A possible mediating effect of treated wastewater effluent may come from the unlikely source of estrogenic endocrine disrupting compounds frequently found in treated, municipal wastewater effluent, including the effluents of the Metro WWTP (Barber et al. 2007). Several recent studies have documented increased motility rates of mammalian and fish sperm exposed either directly or in vivo to 17ß-estradiol (Adeoya-Osiguwa et al. 2003; Kleinkauf et al. 2004; Jin et al. 2005). It is possible that the low (ng/L) concentrations of 17ß-estradiol, estrone, and ethynylestradiol in the Metro WWTP effluent (Barber et al. 2007) have an excitatory effect of the exposed sperm that may offset some of the inhibitory properties of effluent with higher osmolality. Although modes of action of sperm activation in effluents were beyond the scope of this study, this unexpected result warrants further investigations.

River water effects on sperm motility parameters varied significantly between sampling days. Just prior to the first sampling event, heavy rain fell upstream of the sampling site in St. Paul and may have influenced concentrations of several cations and metals in the river water samples. The impact of these rain events was not found in the effluent samples (stormwater runoff in the urban area served by the sampled wastewater treatment plant is completely separated from the wastewater stream). Sperm activated in river waters collected during the initial 2 sampling days performed consistently below sperm activated in river waters collected on the later 3 sampling days. It is noteworthy that calcium 
concentrations were markedly higher on the first 2 sampling days in river water (rain event), while potassium concentrations varied little across all 5 river water collection days. Considering the enhancing effects of potassium on sperm motility (Tan-Fermin et al. 1999; however, Alavi et al. (2007) did not report this enhancing effect) and the inhibiting effect of higher calcium concentrations (through increased osmolality) on sperm motility (Alavi et al. 2007), it appears that this field observation is consistent with published laboratory studies in finding diminished motility of goldfish sperm activated in river water immediately after the rain event (high calcium) compared to activations several days later (lower calcium concentrations). Although it was beyond the scope of this study to determine which components of river water were responsible for the observed change in sperm performance, the natural variability of river water must be taken into account if such environments are used as reference sites for studies of effluent effects.

This study's results should provide a cautionary note for field studies in which upstream sites are often assumed to be de facto reference sites to anthropogenically disturbed downstream locals. Furthermore, the pronounced effects of the physicochemical environment of a study site need to be taken into consideration when an attempt is made to compare field sites with each other. This study should be followed up with an analysis of the actual fertilization rate of eggs in the presence of sperm activated in media of varying osmolality, although these would be complicated by the confounding variable of the effects of the medium on the egg. Finally, the complexity of sometimes contradictory effects in organisms exposed to different physicochemical environments underscores the complexity of vertebrate physiology and the difficulties associated with developing robust experimental designs for studies in aquatic toxicology.

Acknowledgments The authors thank P. Sorensen for laboratory facilities, M. Troedsson (University of Minnesota) for making the computer-assisted sperm analyzer available to us, and K. Loseth for providing training on its use. Glen Parsons at the University of Mississippi determined the osmolality of the activation solutions. B. Polta provided logistical support. Two anonymous reviewers provided excellent suggestions for improving this manuscript. This work is the result of research sponsored by the Minnesota Sea Grant College Program supported by the NOAA Office of Sea Grant, U.S. Department of Commerce, under Grant NOAA-NA86-RG0033.

\section{References}

Adeoya-Osiguwa SA, Markoulaki S, Pocock V, Milligan SR, Fraser LR (2003) 173 estradiol and environmental estrogens significantly affect mammalian sperm function. Human Reprod 18:100-107. doi:10.1093/humrep/deg037

Alavi SMH, Cosson J (2005) Sperm motility in fishes. I. Effects of temperature and $\mathrm{pH}$ : a review. Cell Biol Int 29:101-110. doi: 10.1016/j.cellbi.2004.11.021
Alavi SMH, Rodina M, Policar T, Jozak P, Psenicka M, Linhart O (2007) Semen of Perca fluviatilis L.: sperm volume and density, seminal plasma indices and effects of dilution ratio, ions and osmolality on sperm motility. Theriogenology 68:276-283. doi: 10.1016/j.theriogenology.2007.05.045

Astanin LP, Podgornyy MI (1968) Features of the fertility of Carassius carassius (L.) and Carassius auratus gibelio (Bloch). J Ichthyol 8:209-214

Barber LB, Lee KE, Swackhamer DL, Schoenfuss HL (2007) Reproductive responses of male fathead minnows exposed to wastewater treatment plant effluent, effluent treated with XAD8 resin, and an environmentally relevant mixture of alkylphenol compounds. Aquat Toxicol 82:36-46. doi:10.1016/j.aquatox. 2007.01.003

Billard R (1978) Changes in structure and fertilization ability of marine and freshwater fish spermatozoa diluted in media of various salinities. Aquaculture 14:187-198. doi:10.1016/00448486(78)90094-7

Billard R, Cosson J, Perchec G, Linhart O (1995) Biology of sperm and artificial reproduction in carp. Aquaculture 129:95-112. doi: 10.1016/0044-8486(94)00231-C

Carroll AM, Wainwright PC, Huskey SH, Collar DC, Turigan RG (2004) Morphology predicts suction feeding performance in centrachid fishes. J Exp Biol 207:3873-3881. doi:10.1242/jeb.01227

Chao N, Chao W, Liu K, Liao I (1987) The properties of tilapia sperm and its cryopreservation. J Fish Biol 30:107-118. doi: 10.1111/j.1095-8649.1987.tb05737.x

Christ S, Toth G, McCarthy H, Torsella J, Smith M (1996) Monthly variation in sperm motility in common carp assessed using computer-assisted sperm analysis (CASA). J Fish Biol 48:12101222. doi:10.1111/j.1095-8649.1996.tb01815.x

Coutant C (1970) Biological aspects of thermal pollution. I. Entrainment and discharge canal effects. Rev Environ Control $1: 342-381$

DeFraipont M, Sorensen PW (1993) Exposure to the pheromone 17a, 20b-dihydroxy-4-pregnen-3-one enhances the behavioral spawning success, sperm production and sperm motility of male goldfish. Anim Behav 46:245-256. doi:10.1006/anbe.1993.1186

Desbrow C, Routledge E, Brighty G, Sumpter J, Waldock M (1998) Identification of estrogenic chemicals in STW effluent. I. Chemical fractionation and in vitro biological screening. Environ Sci Technol 32:1549-1558. doi:10.1021/es9707973

Dzuba B, Bozhok G, Rudenko S (2001) A study of the dynamics of volume change during the period of active motility in carp, Cyprinus carpio L., spermatozoa. Aquacult Res 31:51-56. doi: 10.1046/j.1365-2109.2001.00527.x

Farley CT (1997) Maximum speed and mechanical power output in lizards. J Exp Biol 200:2189-2195

Fassel VA, Kniseley RN (1974) Inductively coupled plasma optical emission spectroscopy. Anal Chem 46:1110A-1120A. doi: 10.1021/ac60349a023

Folmar L, Denslow N, Rao V, Chow M, Crain A, Enblom J, Marcino J, Guillette L Jr (1996) Vitellogenin introduction and reduced serum testosterone concentrations in feral male carp (Cyprinus carpio) captured near a major metropolitan wastewater treatment plant. Environ Health Perspect 104:1096-1100. doi:10.2307/ 3433123

Folmar L, Denslow N, Kroll K, Orlando E, Enblom J, Marcino J, Metcalfe C, Guilette L Jr (2001) Altered serum sex steroids and vitellogenin induction in walleye (Stizostedion vitreum) collected near a metropolitan wastewater treatment plant. Arch Environ Contam Toxicol 40:392-398. doi:10.1007/s0024 40010188

Full RJ, Yamauchi A, Jindrich DL (1995) Maximum single leg force production: cockroaches righting on photoelastic gelatin. J Exp Biol 198:2441-2452 
Jin W, Arai KY, Watanabe G, Suzuki AK, Takahashi S, Taya K (2005) The stimulatory role of estrogen on sperm motility in the male golden hamster (Mesocricetus auratus). J Androl 26:478484. doi: 10.2164 /jandrol.04167

Jobling S, Nolan M, Tyler C, Brighty G, Sumpter J (1998) Widespread sexual disruption in wild fish. Environ Sci Technol 32:2498-2506. doi:10.1021/es9710870

Kime DE (1999) A strategy for assessing the effects of xenobiotics on fish reproduction. Sci Total Environ 225:3-11. doi:10.1016/ S0048-9697(98)00328-3

Kime DE, Nash JP (1999) Gamete viability as an indicator of reproductive endocrine disruption in fish. Sci Total Environ 233:123-129. doi:10.1016/S0048-9697(99)00219-3

Kime DE, Ebrahimi M, Nysten K, Roelants I, Rurangwa E, Moore H, Olivier F (1996) Use of computer assisted sperm analysis (CASA) for monitoring the effects of pollution on sperm quality of fish. Application to the effects of heavy metals. Aquat Toxicol 36:223-237. doi:10.1016/S0166-445X(96)00806-5

Kime DE, Van Look K, McAllister B, Huyskens G, Rurangwa E, Ollevier F (2001) Computer-assisted sperm analysis (CASA) as a tool for monitoring sperm quality in fish. Comp Biochem Physiol C 130:425-433

Kleinkauf A, Macfarlane C, Yeates S, Simpson MG, Leah RT (2004) A biomarker approach to endocrine disruption in flounder-estrogen receptors, hepatocyte proliferation and sperm motility. Ecotoxicol Environ Safety 58:324-334. doi:10.1016/j.ecoenv.2003.10.004

Kolpin DW, Furlong ET, Meyer MT, Thurman EM, Zaugg SD, Barber LB, Buxton HT (2002) Pharmaceuticals, hormones, and other organic wastewater contaminants in U.S. streams, 19992000: A national reconnaissance. Environ Sci Technol 36:12021211. doi:10.1021/es011055j

Krasznai Z, Marian T, Balkay L, Gaspar R Jr, Tron L (1995) Potassium channels regulate hypo-osmotic schock-induced motility of common carp (Cyprinus carpio) sperm. Aquaculture 129:123-128. doi:10.1016/0044-8486(94)00234-F)

Krasznai Z, Marian T, Izumi H, Damjanovich S, Balkay L, Tron L, Morisawa M (2000) Membrane hyperpolarization removes inactivation of $\mathrm{Ca} 2+$ channels, leading to $\mathrm{Ca} 2+$ influx and subsequent initiation of sperm motility in the common carp. Proc Natl Acad Sci USA 97:2052-2057. doi:10.1073/pnas.040558097

Kyle A, Stacey N, Peter R, Billard R (1985) Elevations in gonadotrophin concentrations and milt volumes as a result of spawning behavior in the goldfish. Gen Comp Endrocrinol 57:10-22. doi:10.1016/0016-6480(85)90195-9

Lahnsteiner F, Berger B, Grubinger F, Weismann T (2005a) The effect of 4-nonylphenol on semen quality, viability of gametes, fertilization success, and embryo and larvae survival in rainbow trout (Oncorhynchus mykiss). Aquat Toxicol 71:297-306. doi: 10.1016/j.aquatox.2004.11.007

Lahnsteiner F, Berger B, Kletzl M, Weismann T (2005b) Effect of bisphenol A on maturation and quality of semen and eggs in brown trout, Salmon trutta f. fario. Aquat Toxicol 75:213-224. doi:10.1016/j.aquatox.2005.08.004

Liu D, Clarke G, Gordon Baker H (1991) Relationship between sperm motility assessed with the Hamilton-Thorn motility analyzer and fertilization rates in vitro. J Androl 12:231-239

Moore H, Akhondi M (1996) Fertilizating capacity of rat spermatozoa is correlated with decline in straight-line velocity measured by continuous computer-aided sperm analysis: Epididymal rat spermatozoa from the proximal cauda have a greater fertilizing capacity in vitro than those from the distal cauda or vas deferans. J Androl 17:50-60

Morisawa M (1994) Cell signaling mechanisms for sperm motility. Zool Sci 11:647-662
Morisawa M, Suzuki K (1980) Osmolality and potassium ion: their role in initiation and sperm motility in teleosts. Science 210:1145-1147. doi:10.1126/science.7444445

Morisawa M, Suzuki K, Shimizu H, Morisawa S, Yasuda K (1983) Effects of osmolality and potassium on motility of spermatozoa from freshwater cyprinid fishes. J Exp Biol 107:95-103

Petersen C, Warner R (1998) Sperm competition in fishes. In: Birkhead TR, Moller AP (eds) Sperm competition and sexual selection. Academic Press, New York, pp 435-464

Rodgers-Gray T, Jobling S, Morris S, Kelly C, Kirby S, Janbakhsh A, Harries J, Waldock M, Sumpter J, Tyler C (2000) Long-term temporal changes in the estrogenic composition of treated wastewater effluent and its biological effects on fish. Environ Sci Technol 34:1521-1528. doi:10.1021/es991059c

Rodgers-Gray T, Jobling S, Kelly C, Morris S, Brighty G, Waldock M, Sumpter Tyler C (2001) Exposure of juvenile roach (Rutilus rutilus) to treated wastewater effluent induces dose-dependent and persistent disruption in gonadal duct development. Environ Sci Technol 35:462-470. doi:10.1021/es001225c

Runnalls T, Hala DN, Sumpter JP (2007) Preliminary studies into the effects of the human pharamecutical Clofibtric acid on sperm parameters in adult fathead minnows. Aquat Toxicol 84:111118. doi:10.1016/j.aquatox.2007.06.005

Rurangwa E, Biegniewska A, Slominska E, Skorkowski E, Ollevier F (2002) Effect of tributyltin on adenylate content and enzyme activities of teleost sperm: a biochemical approach to study the mechanisms of toxicant reduced spermatozoa motility. Comp Biochem Physiol C 131:335-344

Schoenfuss HS, Levitt JT, Van Der Kraak GJ, Sorensen PW (2002) Ten week exposure to treated wastewater effluent discharge has relatively minor, variable effects on reproductive behavior and sperm production in goldfish. Environ Toxicol Chem 21:2185-2190. doi :10.1897/ 1551-5028(2002)021<2185:TWETTS $>2.0 . C O ; 2$

Stacey NE, Chamberlain K, Sorensen P, Dulka J (1987) Milt volume increase in goldfish: interaction of pheromonal and behavioral stimuli. In: Proceedings of the 3rd International Symposium on Reproductive Physiology of Fish, Alberta, Canada

Stacey NE, Fraser E, Sorensen PW, Van Der Kraak G (2000) Milt production in goldfish: regulation by multiple social stimuli. Comp Biochem Physiol B 130:467-476

Stoss J (1983) Fish gamete preservation and spermatozoa physiology. In: Hoar WS, Randall DJ, Donaldson EM (eds) Fish physiology 1X B. Academic Press, New York, pp 305-350

Swanson C, Young PS, Cech JC Jr (1998) Swimming performance of delta smelt: maximum performance, and behavioral and kinematic limitations of swimming at submaximal velocities. J Exp Biol 201:333-345

Takai M, Morisawa M (1995) Change in intracellular K+ concentration caused by external osmolality change regulates sperm motility of marine and freshwater teleosts. J Cell Sci 108:1175-1181

Tan-Fermin J, Miura T, Adachi S, Yamauchi K (1999) Seminal plasma composition, sperm motility, and milt dilution in the Asian catfish Clarias macrocephalus (Gunther). Aquaculture 171:323-338. doi:10.1016/S0044-8486(98)00402-5

Ternes T (1998) Occurrence of drugs in German wastewater treatment plants and rivers. Water Res 32:3245-3260. doi:10.1016/S00431354(98)00099-2

Ternes T, Stumpf M, Mueller J, Haberer K, Wilken R-D, Servos M (1999) Behavior and occurrence of estrogens in municipal wastewater treatment plants. I. Investigations in Germany, Canada, and Brazil. Sci Total Environ 225:81-90. doi: 10.1016/S0048-9697(98)00334-9

U.S. Environmental Protection Agency (1983) Method 200.7. Methods for chemical analysis of water and wastes. EPA-600 4-79- 
020. Environmental Monitoring and Support Laboratory, Office of Research and Development, Cincinnati, $\mathrm{OH}$

Warnecke D, Pluta H-J (2003) Motility and fertilization capacity of frozen/thawed common carp (Cyprinus carpio L.) sperm using dimethyl-acetamide as the main cryoprotectant. Aquaculture 215:167-185. doi:10.1016/S0044-8486(02)00371-X
Wilson R, Franklin CE, James RS (2000) Allometric scaling relationships of jumping performance in the striped marsh frog, Limnodynastes peronii. J Exp Biol 203:1937-1946 